\title{
Inventando el crimen pasional: del lenguaje de gacetilla a la prensa de sucesos (España, 1892-1920)
}

Antonio Laguna Platero antonio.laguna@uv.es Facultad de Periodismo Universidad de Valencia Avda. Blasco Ibáñez, 32 46010 Valencia

Francesc-Andreu Martínez Gallego francesc.martinez@uv.es Facultad de Periodismo Universidad de Valencia Avda. Blasco Ibáñez, 32 46010 Valencia

Resum: El terme "crim passional» va sorgir a la premsa espanyola el i892. L'objectiu d'aquest treball és desvelar el perquè i entendre'n la relació amb la premsa sensacionalista $i$, en especial, amb la premsa especialitzada en successos. La nostra metodologia considera que la premsa és un motor cultural en la construcció de conceptes amb incidència social. Així, doncs, explorem la presència del terme "crim passional» en un bon nombre de diaris i setmanaris per observar com es va construir un marc mental de naturalesa emocional. Es revela la incidència del concepte en l'opinió pública i en el llenguatge jurídic, així com la seva rellevància en la justificació de la violència contra les dones.

Paraules Clau: crim passional, sensacionalisme periodístic, premsa de successos, violència masclista. 


\section{Inventing the crime of passion: from the language \\ of the press to the reporting of events (Spain, 1892-1920)}

Aвstract: The term "crime of passion" emerged in the Spanish press in I892. The aim of this paper is to reveal why, and to understand its importance to the sensationalist press and, especially, to the press specialized in the reporting of events. Our methodology understands the press as a cultural engine involved in the construction of concepts with social impact. Therefore, we scrutinize the presence of the term "crime of passion" in a large number of newspapers and weeklies to observe how a mental framework of an emotional nature was constructed. The impact of the concept on public opinion and legal language is revealed, as well as its relevance in justifying violence against women.

KeYwords: crime of passion, sensationalist journalism, event reporting, male violence.

RESUMEN: El término «crimen pasional» surgió en la prensa española en I892. El objetivo de este trabajo es desvelar el porqué y entender su relación con la prensa sensacionalista y, en especial, con la prensa especializada en sucesos. Nuestra metodología entiende la prensa como un motor cultural en la construcción de conceptos con incidencia social. Así pues, exploramos la presencia del término «crimen pasional» en una gran cantidad de diarios y semanarios para observar cómo se construyó un marco mental de naturaleza emocional. Se revela la incidencia del concepto en la opinión pública y en el lenguaje jurídico, así como su relevancia en la justificación de la violencia contra las mujeres.

Palabras Clave: crimen pasional, sensacionalismo periodístico, prensa de sucesos, violencia machista.

\section{Introducción: la pasión y los códigos normativos}

Cuando Benedetto Croce decía que «los requerimientos prácticos que laten bajo cada juicio histórico dan a toda la historia carácter de

Cercles. Revista d'Història Cultural, 24 (2021), 47-78.

ISSN: 1139-0158. e-ISSN: 1699-7468. DOI: 10.1344/cercles2021.24.1002. 
historia contemporánea, por lejanos en el tiempo que puedan parecer los hechos por ella referidos; la historia, en realidad, está en relación con las necesidades actuales y la situación presente en que vibran aquellos hechos», ${ }^{\mathrm{H}}$ nos proponía a los historiadores que tomásemos conciencia de los interrogantes que cabe plantear al pasado para entender el presente. Pues bien, uno de los asuntos de la agenda social internacional en los últimos años es el de la confrontación con la violencia de género en nuestras sociedades configuradas desde el patriarcado. ${ }^{2}$ En 20I7, la Corte Interamericana de Derechos Humanos advirtió que el concepto de crimen pasional forma parte del estereotipo que justifica la violencia contra la mujer. El adjetivo pasional le confiere un móvil «involuntario» al agresor y hasta culpabiliza a la víctima, pues ella ha sido la causante de dicha pasión. ${ }^{3}$

Sin embargo, es un concepto bien anclado. Según el diccionario de la RAE, el crimen pasional es un homicidio causado por sentimientos como los celos, la ira o el desengaño. Un reconocido estudio sobre la neurología de la pasión afirma: «Las razones misteriosas que generan el comportamiento apasionado pueden actuar incesantemente en una misma persona desplazando a un segundo orden el resto de sus funciones intelectuales o emocionales e, incluso, las más elementales necesidades fisiológicas. Esta conducta también puede anular las formas éticas [...] El individuo actúa endiabladamente poseído, sordo

I Benedetto Croce, La historia como hazaña de la libertad, Ciudad de México, Fondo de Cultura Económica, 2005 , p. I8.

2 Laura Gutman, Amor o dominación: los estragos del patriarcado, Buenos Aires, Del Nuevo Extremo, 20I2; y Lola Venegas, Isabel M. Reverte y Margó Venegas, La guerra más larga de la historia, Barcelona, Espasa, 2019.

3 Corte Interamericana de Derechos Humanos, Caso Gutiérrez Hernández y otros VS. Guatemala. Sentencia de 24 de agosto de 20I7. Véase también Rosa Rodríguez, "Del crimen pasional a la violencia de género: evolución y su tratamiento periodístico», Ámbitos, núm. 17, 2008, pp. I7I-I88. 
a sus códigos». ${ }^{4}$ Georges Bataille lo resumió de manera más literaria diciendo que el Mal es el mejor medio de expresar la pasión. ${ }^{5}$

$\mathrm{Y}$, sin embargo, la pasión es domeñable, educable. ${ }^{6}$ Es histórica. No se trata de devaluarla ni de confrontarla sistemáticamente, y en sentido peyorativo, con la razón, como ha insistido Martha Nussbaum; ${ }^{7}$ pero tampoco de convertirla en exculpatoria, en el vaciadero por donde escapa la responsabilidad. De lo contrario, sería perfectamente lícita la defensa jurídica del criminal basada en que el sujeto está compelido por una emoción más fuerte que su voluntad. Y, sin embargo, durante mucho tiempo, esto fue (¿sigue siendo?) así. La pasión tendió a justificar el crimen. La tendencia a largo plazo al descenso de la violencia interpersonal ${ }^{8}$ encontró una excusa cultural. El proceso civilizatorio se topó con la exaltación pasional. ${ }^{9}$

En el Código Penal español de i822 se contemplaban como atenuantes del delito «los sentimientos y los móviles apasionados, expresamente cuando se hubiera actuado por indigencia, amor, amistad, gratitud, ligereza o arrebato de una pasión» (art. I07. 2) y el Código de I848

4 Alberto Porteza, «Cerebro y pasiones», en Botella y J. A. F. Tresguerres (eds.), Hormonas, instintos y emociones, Madrid, Editorial Complutense, 1996, p. 83.

5 Georges Bataille, La literatura y el mal, Ediciones elaleph.com, 2000, p. 30.

6 Myriam Jimeno, Crimen pasional. Contribución a una antropología de las emociones, Bogotá, Universidad Nacional de Colombia, 2004.

7 Martha Nussbaum, Paisajes del pensamiento: la inteligencia de las emociones, Barcelona, Paidós, 2008.

8 Ted Robert GuRR, «Historical trends in violent crime: a critical review of the evidence», Crime and Justice. An Annual Review of Research, núm. 2, 198I, p. 306 y ss.

9 La influencia de Norbert Elias ha sido evidente en la explicación del descenso de la violencia interpersonal. Véase Pieter SPIerenburg, «Violence and the civilizing process: does it Work?», Crime, Histoire et Sociétés, vol. 5, núm. 2, 200I, pp. 87-Io5; y Carolyn Strange y Robert CRibB, «Historical perspectives on honour, violence and emotion», en C. Strange, R. CribB y C.R. Forth (eds.), Honour, Violence and Emotions in History, Londres, Bloomsbury Kindle Edition, 20I4, pp. I-22. El libro de referencia es Norbert Elias, El proceso de civilización. Investigaciones sociogenéticas y psicogenéticas, Ciudad de México, Fondo de Cultura Económica, 1993.

Cercles. Revista d'Història Cultural, 24 (2021), 47-78.

ISSN: 1139-0158. e-ISSN: 1699-7468. DOI: 10.1344/cercles2021.24.1002. 
mantuvo una fórmula similar. ${ }^{\text {Io }}$ Eran los denominados por la prensa de entonces, también en el ámbito forense, crímenes de honor, puesto que el término "crimen pasional» todavía no había aparecido. ${ }^{\text {II }}$ El Código Penal de I870 regulaba los delitos contra la honestidad (título IX) y no solo protegía la moral sexual de la época, sino que garantizaba la impunidad del varón: solo «la mujer casada que yace con varón que no sea su marido» incurría en delito; nunca al revés. El mismo código expresaba que era circunstancia atenuante de responsabilidad criminal «la de haber ejecutado el hecho en vindicación próxima de una ofensa grave». Si se combinan los dos artículos, el resultado es evidente.

Si el Código Penal no era suficiente para la construcción de un imaginario femenino subyugado al masculino, en su ayuda acudió el Código Civil, aprobado en I889. En él, al hablar «De los derechos y obligaciones entre marido y mujer», se establece la obligación de la mujer de obedecer al hombre, así como las prerrogativas del esposo sobre la persona de su mujer y sobre los bienes de la sociedad conyugal. A esta incapacitación de la mujer se añade que el Código señala como causa de divorcio el adulterio de la mujer, porque, si se trata del hombre, debe concurrir el «escándalo público o el menos precio de la mujer». También se citan como causa de divorcio los malos tratos, pero solo cuando un cónyuge intentase forzar al otro a cambiar de religión.

Las imágenes y las representaciones culturales tienen una gran relevancia en la formación de identidades sociales y en la inducción

io Leopoldo Puente Segura, Circunstancias eximentes, atenuantes y agravantes de la responsabilidad criminal, Madrid, Colex, 1997.

II Gutmaro Gómez Bravo, «La violencia y sus dinámicas: crimen y castigo en el siglo XIX español», Historia Social, núm. 51, 2005, pp. 93-IIO. Sobre el concepto de honor y su trasiego histórico, véase el relato microhistórico contenido en Pablo RodríGuez, Historia de un crimen pasional. El caso Zawadzky, Bogotá, Editorial Universidad del Rosario, 20I9; así como Pieter Spierenburg, «Violencia, castigo, el cuerpo y el honor: una revaluación», en V. WeILER (comp.), Figuraciones en proceso, Bogotá, Universidad Nacional - Universidad Industrial de Santander - Fundación Social, I998, y Anton BLok, Honour and Violence, Oxford y Cambridge, Polity Press, 200I 
o legitimación de prácticas sociales. ${ }^{\mathrm{I2}}$ La ideología de la domesticidad en la España del siglo xIX era una amalgama de nociones tradicionales, ideas religiosas y valores burgueses; establecía que no podía haber igualdad entre quienes no son iguales y que la meta de la mujer, un ser inferior, era el matrimonio y la maternidad: su mejor destino era ser ángel del hogar. ${ }^{13}$ La subordinación de la mujer al hombre continuó durante buena parte del siglo xx.

Así pues, cuando un hombre asesinaba a una mujer, resultaba más que conveniente a su abogado ampararse en móviles como el resentimiento, el honor o la pasión, puesto que obtenían con mucha frecuencia la calificación de homicidio y no de asesinato. En un estudio pormenorizado sobre la provincia de Córdoba en el primer tercio del siglo xx, cuando el crimen pasional ya era un marbete frecuente, las causas que se relatan como soliviantadoras de la pasión son: «en primer lugar, por la oposición de los familiares de la joven a la relación; en segundo lugar, por la negativa de la joven a los requerimientos amorosos de un varón; en tercer lugar, por la lucha de dos pretendientes por una sola mujer. Y, en cuarto lugar, por adulterio, donde la mujer se queda al margen». ${ }^{14}$

Llegados a este punto, establezcamos coincidencias. Hasta la década de 1890 - ahora lo veremos con precisión-, el crimen pasional no existe: no lo mencionan ni códigos penales ni fiscales ni abogados en los juicios. No lo menciona la prensa. Existen delitos en los que el honor está presente y sirve como eximente o atenuante, aunque, cuando se trata de violencia contra las mujeres, por su condición de tales no hace mucha falta, dada la condición subalterna que les deparan los códigos y la jurisprudencia.

I2 Mary NaSh (ed.), Feminidades y masculinidades. Arquetipos y prácticas de género, Madrid, Alianza, 20I4, p. I8.

I3 Nerea Aresti, "El ángel del hogar y sus demonios. Ciencia, religión y género en la España del siglo XIX», Historia Contemporánea, núm. 2I, 2000, pp. 363-394.

I4 Raúl Ramírez, "Estudio sobre la violencia contra la mujer en el primer tercio del siglo xx: la provincia de Córdoba", Arenal, núm. 22-I, 20I5, pp. I2I-I55.

Cercles. Revista d'Història Cultural, 24 (2021), 47-78.

ISSN: 1139-0158. e-ISSN: 1699-7468. DOI: 10.1344/cercles2021.24.1002. 
El crimen pasional cobra carta de naturaleza al poco tiempo de la aprobación del Código Civil, que subordina la mujer al hombre, cuando surgen, de la mano de Emilia Pardo Bazán y otras, las primeras vindicaciones de la igualdad educativa para hombres y mujeres y la coeducación; ${ }^{15}$ cuando aparecen las primeras mujeres vinculadas a organizaciones obreras — caso de la anarquista Teresa Claramuntque promueven la movilización en favor de la causa de la igualdad de género; justo cuando nace, de la mano de Ángeles López de Ayala, Amalia Domingo y la misma Teresa Claramunt, la Sociedad Progresiva Femenina, en Barcelona, que establecía el postulado de la emancipación de la mujer ${ }^{16}$ cuando surgía el periodismo sensacionalista en España y en el mundo, el cual, no se olvide, es la clave de cómo los periódicos cambiaron a lo largo del siglo, al atraer por miles a lectores que, hasta entonces, habían quedado fuera de su foco. ${ }^{17}$

Estas coincidencias sirven para establecer las hipótesis y los interrogantes del presente estudio. El crimen pasional, como expresión, es un recurso periodístico enteramente novedoso en la década de I890, construido — casi con toda seguridad importado de la prensa francesa $-{ }^{18}$ para dotar de dramatismo a acontecimientos de los que

I5 Pilar Folguera, «Revolución y Restauración. La emergencia de los primeros ideales emancipadores", en E. Garrido, P. Folguera, M. Ortega y C. Segura (eds.), Historia de las mujeres en España, Madrid, Síntesis, 1997, pp. 464-465.

I6 Laura Vicente, Teresa Claramunt. Pionera del feminismo obrerista anarquista, Madrid, Fundación Anselmo Lorenzo, 2006.

I7 La cita pertenece a la introducción de David B. Schsman y David W. Bulla (eds.), Sensationalism: Murder, Mayhem, Mudslinging, Scandals, and Disasters in I9th-Century Reporting, New Brunswick, NJ, Transaction Publishers, 2013. Para adentrarse en el caso español, véase Francesc-Andreu Martínez y Antonio Laguna, Sangre, miedo y evasión: el sensacionalismo periodístico en España, Madrid, Fragua, 2020; y para Iberoamérica, F. A. Martínez, J. L. Gómez, L. F. Estrada, J. Moyano y P. Vega, Orígenes y consolidación del sensacionalismo periodístico en Iberoamérica, Madrid, Fragua, 2020.

I8 En la prensa francesa apareció en la década de I880; véase Anne-Claude AmbroiseRENDU, «Et la presse inventa le crime passionnel», L'Histoire, núm. I68, 1993, pp. 98-Ioo. La prensa española menciona continuamente crímenes franceses antes de acuñar el término. 
se pretende realizar una descripción detallada, adjetivada, vinculada a la hipérbole y a la hipotiposis.

Pero, además, la expresión crimen pasional sirvió para confrontar razón y pasión en torno al estereotipo femenino, Por tanto, ellas eran pasionales o desataban las pasiones ajenas, de manera que, en cualquier caso, merecían la condición subordinada que los códigos legales y las convenciones sociales les deparaban. Esto incluía, claro está, la desautorización de cualquier voz o movimiento en favor de la igualdad de los géneros o de la emancipación de las mujeres.

Por fin, nuestra hipótesis añade que el término «crimen pasional» hizo fortuna. En tanto en cuanto la prensa construye una cultura, un gusto, una moral social, ${ }^{19}$ la adjetivación sensacionalista pasional se convirtió en un marco de interpretación social para los crímenes perpetrados contra mujeres o en los que las mujeres resultaban cosificadas como objetos en disputa. El crimen pasional mediatizó la vida afectiva, construyó una sensibilidad. ${ }^{20}$

\section{Crímenes folletinescos}

El sensacionalismo periodístico era una gran máquina de reciclaje. Los tópicos del crimen pasional hacía tiempo que estaban presentes en las relaciones de sucesos, en la literatura de cordel, en el folletín. ${ }^{2 \mathrm{I}}$

\footnotetext{
Véase también Annik Honel, Patricia Mercader y Helga Sobota, Crime passionnel, crime ordinaire?, París, Presses Universitaires de France, 2003, pp. 3I-49; y Joëlle GuILLAIs, Le crime passionnel au XIX siècle, obras en las que se establece la relación entre folletín, novela romántica y la expresión crimen pasional.

I9 Christophe Charle, Le siècle de la presse (I830-1939), París, Seuil, 2004, pp. I8-20.

20 Lucien Febvre, "La sensibilité et l'histoire: Comment reconstituer la vie affective d'autrefois?», Annales d'histoire sociale, tomo 2, núm. I-2, enero-junio I94I, pp. 5-20.

2I A título de ejemplo, la relación «Memorable suceso que este año de mil y seis-

Cercles. Revista d'Història Cultural, 24 (2021), 47-78.

ISSN: 1139-0158. e-ISSN: 1699-7468. DOI: 10.1344/cercles2021.24.1002.
} 
Invitaban a refocilarse en la atracción secular por el espectáculo de la muerte. La vivencia de la muerte - y, por supuesto, del dolor-, varía según el tiempo y el lugar, por lo que tendría un componente cultural inequívoco. La respuesta, por tanto, a la pregunta de por qué la muerte atrae la atención y la curiosidad morbosa no puede basarse solo en motivos fisiológicos o psicológicos, en este caso, relacionados con una pulsión irracional de todo ser humano por liberar miedos o por un deseo innato de conocer lo prohibido y oculto, al que llamamos morbo. Las emociones se interpretan y se evalúan, sobre todo, en función del sistema de valores imperante, de quién las promueve y distribuye y de quién las consume y procesa. Es preciso, por lo tanto, establecer en plano de igualdad, por un lado, la identificación del poder, que recurre al espectáculo del dolor y al mensaje del miedo para inocular sumisión y acatamiento, y, por otro, unas capas populares que viven el espectáculo de la muerte como una forma de diversión y, por eso mismo, también de enajenación. De hecho, una de las interpretaciones más seguidas acerca de por qué atrae tanto la noticia emotiva, luctuosa y sensacional es por su efecto psicológico de liberación y/o evasión de la realidad. Hay incluso quienes establecen una relación entre el dolor físico y el placer sexual, sobre todo a la hora de explicar los castigos físicos en el ámbito de la religión. Vandermeersch, en su estudio sobre los flagelantes, señala cómo sadismo y masoquismo son fenómenos simétricos que

cientos y veinte y cuatro a veinte y cinco del mes de octubre, se vido en Sevilla, escrito a un amigo, en que le da cuenta de cómo un hombre aviendo preso a su muger por adúltera, y sentenciados a degollar por manos de su marido, se le entregaron en un cadahalso, para que executase la sentencia; declárase el principio del caso, el medio que tuvo, y el buen fin que se consiguió». Impreso con licencia en Sevilla por Manuel Ximénez, año de I624; transcrito en Manuel Bernal y Carmen Espejo, «Tres relaciones de sucesos del siglo Xvir. Propuesta de recuperación de textos preperiodísticos», IC Revista Científica de Información y Comunicación, núm. I, 2003, pp. 133-176. Para el caso francés, véase Annick Honel, Patricia Mercader y Helga Sobota, op. cit.,, pp. 3i-49; y Joëlle Guillais, op. cit... 
tienen en el dolor su común denominador, y cómo la flagelación puede ir asociada a emociones sexuales. ${ }^{22}$

La importancia informativa de la muerte evolucionó a medida que progresaba el siglo xix. En el caso español, la prensa informa de las ejecuciones con el mismo tono que describe los debates parlamentarios o los acontecimientos políticos. Entre los años treinta y ochenta del siglo XIX , la descripción somera de los hechos y el resalte del interés del público constituyen las claves básicas de la práctica totalidad de noticias, ofrecidas casi siempre en forma de breves. Tan solo los detalles acerca del comportamiento de los reos, de sus últimas palabras o de las expresiones de los asistentes introducen algunos elementos emocionales en el relato. El único exceso que se detecta en el uso del lenguaje tiene que ver con la gravedad del crimen cometido y es muy ocasional hasta los años noventa del XIX. Así, por ejemplo, el 5 de noviembre de I859, la noticia del asesinato de una mujer por un hombre que quiere tener relaciones con otra, aparecida en La Correspondencia de España, provoca que el texto se inicie con la exclamación de «iHorrible, horrible, horrible!»; lo mismo sucede en la ofrecida por el mismo periódico el i3 de abril de I860, donde el asesinato de una hija a manos de su madre es calificado de «repugnante crimen».

Mientras que la noticia del crimen apenas evoluciona en forma y contenido, el relato de crímenes se convierte en protagonista de una sección que irrumpe con fuerza en la prensa francesa a partir de I836. Es el folletín. Sucede el i de julio de ese año, cuando dos empresarios que aspiran a vender más, para rebajar el precio y conseguir más ingresos por publicidad, ponen en circulación dos nuevos diarios mediante una nueva sección, el folletín. Emile de Girardin, editor de La Presse, y Armand Dutaq, de Le Siècle, antiguos socios y ahora rivales

22 Patrick Vandermeersch, Carne de pasión. Flagelantes y disciplinantes. Contexto histórico-psicológico, Madrid, Trotta, 2004, pp. 266-68.

Cercles. Revista d'Història Cultural, 24 (2021), 47-78.

ISSN: 1139-0158. e-ISSN: 1699-7468. DOI: 10.1344/cercles2021.24.1002. 
con el mismo objetivo, son los inventores de una fórmula, equivalente a la radionovela, el culebrón televisivo o la serie de ficción de las plataformas digitales futuras. Por aquel entonces, democratizar la literatura era sinónimo de introducir el sensacionalismo en la narración. El I4 de mayo de I843, el periódico parisino Satán reconocía abiertamente que los tres factores que decidían la venta de cualquier publicación eran su calidad, su color político y, sobre todo, su folletín, lo que explica la rapidez con que todos los diarios se apuntaron a incrementar el tamaño de sus hojas permitiendo, de esta forma, una mejora en la oferta de contenidos.

La fórmula pronto fue imitada en el resto de Europa. Y por supuesto en España, cuya prensa diaria venía presentando, desde I834, una sección en la parte inferior de la primera plana bajo el paraguas de «Miscelánea», donde tanto se hacían reseñas de libros, críticas de teatro o noticias de costumbres como se relataban cosas curiosas, sección que acabó dando formao al folletín. A partir de i840 se produce una paulatina incorporación de contenidos seriados en tal Miscelánea. El folletín todavía concierne a temas variados, novelas, ensayos de historia, de literatura, de política, etc. En los temas literarios, empiezan a sobresalir historias coherentes con un romanticismo que prima la pasión y los sentimientos. Se trata, inicialmente, de textos breves, que no ocupan más de dos o tres números y que hablan de dramas históricos (como la muerte de César), de acontecimientos luctuosos o de desgracias familiares. En junio de I840, El Corresponsal de Madrid y El Nacional de Barcelona publicaban «Un hombre atroz» que, a lo largo de tres entregas, desgranaba la historia de una infidelidad y las muertes resultantes. El éxito de este relato llevó al Diario de Madrida reproducirlo en septiembre del mismo año. Una vez concluido, el siguiente folletín del mismo periódico fue «Confesión de un criminal inglés la víspera de su ejecución», mientras que El Correo Nacional de Madrid, en el mismo mes de septiembre de 1840 , publicaba la causa seguida en París contra madame Laffargue por haber envenenado a su marido. 
Es evidente que la literatura de emociones, donde la muerte es protagonista, resultó clave para la popularización de la prensa y pasó a ser santo y seña del movimiento romántico. Pero el crimen en la prensa llegó para quedarse. De hecho, sin la emoción que se desprende de las crónicas que describen por capítulos los asesinatos, no sería posible entender el crecimiento del consumo de periódicos por amplios sectores de la población. Del folletín al reportaje de sucesos el periodismo español se hizo mayor de edad, vale decir, sensacionalista y de masas... "Muchos años más tarde, en I888, un periodista comparará la avidez con que el público devoraba las sensacionalistas noticias del crimen de la calle Fuencarral, con la que en I845 esperaba el capítulo correspondiente del folletín». ${ }^{23} \mathrm{El}$ crimen de la calle de Fuencarral circuló en primeras planas de prensa y en populares pliegos de cordel, con probado mimetismo. ${ }^{24}$

Hasta esa década de los ochenta, la presencia de noticias breves sobre acontecimientos luctuosos en la prensa diaria había sido frecuente, sobre todo en la tercera página de las cuatro que componían la edición. Sin embargo, la experiencia vivida con el crimen de la calle Fuencarral —el impacto emocional que generó y el seguimiento tan generalizado que consiguió - iba a constituir un punto de inflexión. Todos los periódicos empezaron a reconocer el interés que el tema

23 María Cruz Seonne, Historia del periodismo en España 2. El siglo XIX, Madrid, Alianza, I983, p. 203. Sobre la intensa relación entre literatura popular, prensa y configuración cultural del gusto, véase Anne-Marie THIESE, Le roman du quotidien. Lecteurs et lectures populaires à la Belle Époque, París, Éditions du Seuil, 2000.

24 En I888, en la calle madrileña de Fuencarral, apareció asesinada la viuda doña Luciana Borcino. La prensa lo convirtió pronto en un crimen de leyenda, al seguir cotidianamente las indagaciones de la policía y el juicio. Se acusó, en un principio, a José Vázquez-Varela, hijo de la víctima, denunciado por la sirvienta Higinia Balaguer. Sin embargo, a la postre, también esta y una posible cómplice, Dolores Ávila, fueron imputadas. Al final, Balaguer confesó y fue condenada por el asesinato, lo que permitió absolver a José Vázquez-Varela. La sentencia no acabó con la polémica generada por la prensa. Los detalles del juicio y del homicidio dieron para mucho más que una nota a pie de página.

Cercles. Revista d'Història Cultural, 24 (2021), 47-78.

ISSN: 1139-0158. e-ISSN: 1699-7468. DOI: 10.1344/cercles2021.24.1002. 
despertaba entre los lectores y, en mayor o menor medida según su línea editorial, empezaron a darle más espacio y mejor tratamiento. La figura del cronista cobró personalidad propia y emergieron nombres tan destacados como el de Luis Bonafoux Quintero (I855-1918), uno de los columnistas más sobresalientes de la prensa madrileña de su tiempo, incluido el célebre semanario republicano El Motín $n^{25}$. A Bonafoux hay quien lo califica como «el periodista español más brillante, admirado, seguido, odiado y temido de los últimos años del siglo XIX y los primeros del XX». ${ }^{26}$ Además de todos estos calificativos, Bonafoux bien podría ser tildado como el maestro de la crónica sensacional, sobre todo en su etapa como corresponsal en París de los diarios El Liberaly Heraldo de Madrid a partir de I893. Como escribió Arturo Mori, «Bonafoux desde París, junto con Gómez Carrillo en sus viajes y Blasco y Dicenta en España, dieron a la crónica fisonomía y perennidad». ${ }^{27}$ Una buena muestra de este particular estilo la encontramos en el recopilatorio Gotas de Sangre: Crímenes y criminales, donde se ofrece una selecta serie de sus crónicas francesas sobre diversos crímenes y ejecuciones que aparecieron a principio del siglo xx en Heraldo de Madrid.

A partir de los años ochenta es muy significativo el incremento de publicaciones «escabrosas» tanto en el ámbito literario como en el

25 José Nakens, director de El Motín, le dedicó una sentida despedida tras conocer su muerte: «Su vida fue una lucha constante contra todo lo falso, lo convencional, lo ridículo y lo injusto. Vivió modestamente, trabajó mucho en favor de los humildes y desheredados, y no comerció con su pluma, que fue lanceta y bisturí, instrumentos que curan. Amó y odió; prodigó ternuras, despertó rencores, y conservó su independencia. Sufrió persecuciones que agigantaron su espíritu, y recibió homenajes que no le ensoberbecieron. Hizo, en fin, la vida de los buenos, de los justos, de los fuertes, y probó las amarguras anejas a todo ser superior. Honremos su memoria imitándole en lo que nos sea posible». El Motín, 7 de noviembre de I9I8.

26 Miguel Ángel DEL ArCo, «Luis Bonafoux, un periodista refractario. El cronista español más importante de entre siglos», Textual \& Visual Media: revista de la Sociedad Española de periodística, núm. 6 (2013), p. I6I.

27 Arturo Mori, «Los periodistas de ayer», El Liberal, 22 de febrero de 1928. 
periodístico. Si la novela de crímenes se consolida como género propio, los folletines de los diarios aumentan de forma notoria su selección de obras en esta línea. ${ }^{28}$ En palabras de un periódico conservador de Madrid: «¡Cómo cunde la literatura salchichera! No es lo peor que hayan [sic] diez millones de españoles que no sepan leer. Lo peor es la lectura que les aguarda cuando aprendan». ${ }^{29}$

\section{2, el desvelamiento del crimen de pasión}

Es el mes de abril de I892 y el periodista de Heraldo de Madrid, Salvador Canales, escribe la crónica de un ajusticiado por la guillotina. Se trata del célebre Anastay. El periodista compara su ejecución con la de Higinia Balaguer, la famosa incursa en el crimen de la calle de Fuencarral, a garrote vil. Y encuentra un argumento extraño contra la pena de muerte: "En la agonía del hombre que desde el lecho se despide de la vida, como en un crimen pasional, por celos, por venganzas de la honra, por hambre - la pasión tremenda- hay algo que nos llega al alma. En la ejecución de un hombre por la sociedad, ¿qué hay de humano? A lo sumo el consuelo de que ése [sic] hombre

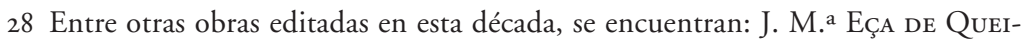
ROZ, El crimen de un clérigo. Novela traducida por un exjesuita, Madrid, Imprenta de Juan Iniesta, I882-1884; El crimen misterioso de Biar. Causa sobre el asesinato de doña Fausta Richard y Bordera, Alicante, J. Marcili, I885; È. Richebourg, El crimen de Grandvale (los millones del señor Foramie), versión española de J. Escudero, Madrid, I885; X. de MoNTÉPIN, El crimen del teniente, Madrid, Imprenta Popular a cargo de Tomás Rey, I885 y El crimen de Asnières, Madrid, Imprenta de Emilio Saco y Brey, I886; A. Racot, El crimen de Darío Fal, Madrid, I888; P. J. Solas, El crimen de Talabarte, Madrid, I887; A. MoyANo, El crimen del Halconero, Medina del Campo, Imprenta de Pablo F. Álvarez, I89ı; R. A. Torres y J. Rodríguez Castro, El crimen de "Las Lomas", informe pericial, Roma, Imprenta «El Vapor», I893. Todas estas obras pueden hallarse en http://www.cervantesvirtual.com.

29 La Atalaya, I2 de febrero de I906, p. 2.

Cercles. Revista d'Història Cultural, 24 (2021), 47-78.

ISSN: 1139-0158. e-ISSN: 1699-7468. DOI: 10.1344/cercles2021.24.1002. 
ya no nos matará a nosotros. ¿Y qué importa un enemigo menos entre tantos millones de enemigos?». ${ }^{30}$

Pocos días después, el 3 I de mayo, cuenta La Libertad, con truculencia, el caso de una joven mujer que, al descubrir que su marido la engaña con su mejor amiga, mata, enloquecida, a su rival. El periodista le pone literatura a este "crimen, sí; pero crimen pasional», al añadir que la asesina ultrajada es criolla, mecida en las pasiones tropicales, de la estirpe de Otelo. Se trata de un crimen largamente comentado por la prensa francesa — La Gaulois, Le Nabab_, lo que invita a pensar que la expresión crimen pasional se importa en ese momento.

El 3 de junio siguiente, La Vanguardia de Barcelona se atreve a escoger como subtítulo «Un crimen pasional». La noticia es común: Ginés Toribio había matado a su amante, María Dolz. Como resultó que ella no estaba dormida, en vez de condenarlo por asesinato, se le condenó por «simple homicidio» a quince años de cárcel..$^{31}$

Con jocosidad, La Caricatura vaticinaba ya en I893:

Volvemos a las andadas. El último crimen pasional — me gusta la palabreja- y la venta del niño, han servido de tema a muchas conversaciones y de pretexto para varias interviews. Periodista hay que remueve hasta las piedras con tal de dar una nota original, nuevecita en la información que corre a su cargo. Apenas un sujeto propina cuatro o seis puñaladas, ya tiene a cuatro o seis noticieros preguntándole:

- ¿Y cuándo imaginó usted el crimen?

- El domingo pasado, al salir de los toros.

- ¿Es usted aficionado?

— No, señor; fui a la corrida por casualidad.

— Entonces, ¿qué afición le subyuga más?

- A mí la de los frontones. El peloteo me atrae.

30 Heraldo de Madrid, I6 de abril de I892, p. 2.

31 La Vanguardia, 3 de junio de I892, p. 2. 
Las prensas gimen para enterar al público de la cara que tiene el asesino de moda, de las prendas de ropa que usa el ladrón más famoso de la quincena y hasta de la alimentación predilecta de cualquiera de los criminales distinguidos del gremio.

Aún no hemos llegado al perfeccionamiento de las noticias, pero se llegará. El mejor día se anunciarán los crímenes como los eclipses, y las empresas de los periódicos de gran circulación contratarán, por sumas considerables, sucesos estupendos $[\ldots] .^{32}$

Así pues, el arranque del crimen pasional es sorprendente. No por su abundancia, comentada en La Caricatura. No por imitación de lo francés, sino porque el crimen pasional «nos llega al alma», es shakespeariano o es simple homicidio». ${ }^{33} \mathrm{El}$ circunspecto y conservador La Época utiliza también la expresión en el mes de junio de ese año inaugural: se burla de las mujeres que opinan, como madame Adam, que afirma que «la justicia no puede legislar sobre la pasión. [...] Condenemos el crimen pasional por salvaje». ${ }^{34} \mathrm{Y}$, de este modo, la juiciosa expresión de alguien que pide que la pasión no se considere móvil de un acto salvaje queda relegada como "cosa de mujeres».

En I893, El Isleño, modesto periódico de Palma de Mallorca, refería las declaraciones de un célebre médico francés, Dumontpallier, que, como madame Adam, creía que el crimen estaba siendo motejado por la prensa como "crimen de alcohólico», "crimen pasional» o "crimen de alienado» y que no se entendía muy bien el criterio

32 La Caricatura, 23 de abril de 1893,2 . Al inicio del artículo, al hablar del niño se hace referencia a la popular lotería cuyo sorteo se efectúa el 6 de enero.

33 Sobre el origen francés de la expresión, véase Eliza E. FERGuson, «Emotion gender and honor in a fin-de-siècle crime of passion: The case of Marie Biere», op. cit., en C. STranGe, R. Cribb, y C. Forth (eds.), op. cit., pp. I45-I62. Sobre su difusión, véase Saydi Núñez, «Entre la emoción y el honor: crimen pasional, género y justicia en la ciudad de México, 1929-I97I", Estudios de Historia Moderna y Contemporánea de México, 50, 2015, pp. 28-44.

34 La Época, 6 de junio de I892, p. 4. 
jurídico que animaba tales etiquetas: «¿Qué hará el jurado que haya de examinar esos crímenes? ¿Puede un hombre, en conciencia, decir al primer asesino que se le presente: «-Yo te absuelvo, porque eres un alcohólico, y por consiguiente irresponsable?».35

Con estos ribetes, el uso de la expresión crimen pasional se generaliza rápidamente. Da buenos resultados. El crimen pasional no es el único que nutre la crónica de sucesos. En su estudio sobre los mismos, Víctor-José Ortega realiza una detallada clasificación que se agrupa en una veintena de variables para recoger actos contra la integridad física de las personas, actos contra la propiedad privada, accidentes, lesiones, actos contra las costumbres y la moral, sucesos catastróficos, sucesos varios y el reforzamiento de la autoridad a través de detenciones, procesamientos o ejecuciones. ${ }^{36}$ Dentro de esta variada crónica roja, el crimen pasional tiene la ventaja de reinventar una fórmula dramática y folletinesca: hace que el público lector espere una compleja historia de amor, celos y engaño tras cualquier acto de esta naturaleza.

El gerundense La Lucha reconocía en I894 que «la prensa, que hemos dado en llamar de circulación, tiene que dar al público noticias que devorar; y así como los confiteros con dos claras de huevo bien batidas hacen un plato que abulta mucho aunque tiene poca verdad, así también con una noticia se prepara un crimen pasional que hace vender algunos números». ${ }^{37}$

El Eco de Navarra reflexionaba sobre la acumulación de sucesos en la prensa:

Podremos haber pasado la vista distraídos por los artículos y sueltos políticos y literarios; pero en cambio hemos devorado el hecho palpi-

35 El Isleño, 6 de septiembre de I893, pp. I-2. También se hizo eco el periódico gerundense El Independiente, I de octubre de I893, p. I.

36 Víctor-José Ortega Muñoz, ;Extra, extra! Poder, información y control de la Sociedad española en las noticias de sucesos, I88I-I923, Zaragoza, Libros Pórtico, 2018.

37 La Lucha, I4 de marzo de I894. 
tante, el suceso de actualidad, el hijo o los hijos del pueblo que se han agujereado el cuerpo en una querella, la mujer asesinada por el hombre que le pide el amor o la vida (crimen pasional en lenguaje de gacetilla), el suicidio o los suicidios por miedo a la justicia y por horror a la miseria. [...] Es la barbarie, por contagio, y la prensa la encargada de esparcir diariamente el fomen [sic] a miles y miles de ejemplares. [...] El noticierismo, en el terreno en que acabamos de considerarle, no es más que una especulación patibularia, que engendra en los espíritus y por lo tanto en los hechos, el hábito de la ferocidad. ${ }^{38}$

El periódico navarro proponía «vigilar lo que se escribe», embridar tanto crimen pasional a través de la censura. El satírico burgalés $\mathrm{El} \mathrm{Pa-}$ pa-Moscas no llegaba a tal conclusión, pero coincidía en las premisas:

El proceso del doctor Queipo, del que toda España tiene conocimiento, es un síntoma gravísimo que debe hacer meditar a los hombres pensadores. La información nos ahoga; el deseo de dar noticias de sensación que halaguen las pasiones malsanas de las masas, la especulación periodística que tuvo grandes éxitos con el crimen de la calle de Fuencarral, los inventos de Peral y el crimen de la duquesa de Castro Enríquez, nos han hecho perder la cabeza, y lectores y reporters y el público y hasta los tribunales, si no se dejan influir por la avidez de noticias de sensación, dan pretexto para que así se crea. En el momento que, con razón o sin ella, se acusa a cualquiera de un crimen pasional, la opinión se solivianta, crece la venta de periódicos, y los actuarios y hasta alguien más, parece que van buscando bombos y que se enorgullecen cuando dice un periódico: «El distinguido y activo secretario señor Menzáñez no se ha dado punto de reposo en la noche pasada para realizar ciertos pasos al objeto del completo desenvolvimiento del horroroso crimen de tal». Y este afán de bombo y esta curiosidad malsana

38 El Eco de Navarra, 2i de octubre de i894. El término fomen resulta extraño y aparece en cursiva en el original. Probablemente el autor quiso decir ferment (fermento), vocablo francés e inglés con sentido en la frase.

Cercles. Revista d'Història Cultural, 24 (2021), 47-78.

ISSN: 1139-0158. e-ISSN: 1699-7468. DOI: 10.1344/cercles2021.24.1002. 
y este hacer literatura criminal pone a cualquier hombre honrado en la picota de la deshonra. ${ }^{39}$

Mucho más práctico, como la mayoría, el Heraldo de Baleares llenaba sus páginas con crímenes y en septiembre de I896 su primera página ofrecía uno bien sonado. ${ }^{40} \mathrm{Si}$ pasionales, más atractivos, por lo visto, para el público lector. Lo hacía también La Correspondencia de España: su scoop sobre un crimen pasional en la Valencia de agosto de 1896 lo reproducían El Cantábrico (Santander), El Bien Público (Mahón), La Tempestad (Segovia), etc. El Lábaro afirmaba que los crímenes pasionales, desde luego, no eran nuevos, pero «lo que es alarmante es la frecuencia con que hoy se repiten». Y acudía a un sabio francés, Proal, para determinar las causas: «la precocidad de la juventud en el libertinaje, la mala educación, los progresos del alcoholismo, el relajamiento de los frenos morales y sociales, la sed desenfrenada de goces, la indulgencia del jurado para los delitos de esta clase, la lectura de periódicos y novelas y la representación de dramas por sofismas que cierta literatura ha inventado para excusar los crímenes pasionales». El periódico solicitaba no embellecer el crimen, puesto que la imitación resultaba el mayor de los riesgos. ${ }^{4 \mathrm{I}} \mathrm{La}$ atenta escritora Emilia Pardo Bazán ponía la nota pesimista del gremio al que pertenecía. El público, venía a decir, en vez de discutir la obra de Macías Picavea y reflexionar sobre «el problema de España», se comportaba de manera nada enjundiosa:

El lector pide extensas revistas taurinas, del género inaguantable, con los ceceíllos patosos y los barbarismos achulados tan en moda; quiere además que le tengan al corriente de las probabilidades máximas y

39 El Papa-Moscas, 24 de febrero de 1896.

40 Heraldo de Baleares, 30 de agosto de 1896.

4I El Lábaro, 2I de octubre de I897. 
mínimas que en Barba del Puerco o en La Ajosa reúne la candidatura del niño cunero Rafulánez o Menrengánez; no perdona el escándalo de la calle $\mathrm{H}$ o $\mathrm{B}$, ni el «drama conyugal» ni el «crimen pasional», ni el infundio, ni el timo, ni la bronca, ni la culebra — en la taberna del Gordo o del Mellao; pero que no le vengan a dar la lata (así se habla, y entre gentes de levita o frac) con todo eso de la educación, de la agricultura, de la cultura nacional, del problema económico y del plan curativo aplicable al cuerpo enfermo. ${ }^{42}$

No harán falta más pruebas. En I892 surge el crimen pasional y a partir de 1893 comienza un duelo a florete dialéctico entre los periódicos que quieren ganar lectores llenando sus páginas con crónicas hipotipósicas de crímenes y sucesos morbosos y aquellos otros que dicen aborrecer dicha práctica y que la lamentan. En la última década del siglo xIX se inventa el crimen pasional cuando la prensa lo necesita, cuando el nuevo paradigma criminológico de la imitación comienza a parecerse a la nueva creencia periodística: es posible que lectores imiten a lectores, si el asunto es truculento, y que el periódico crezca en tirada y difusión. El crimen, el suceso, es lo suficientemente pujante como para crear una prensa especializada, que en España cobrará forma de revista semanal o quincenal.

\section{La prensa de sucesos a la caza del crimen pasional}

El primer periódico de sucesos conocido nace en Nueva York en I845, con el nombre de Police National Gazette. Creado por el periodista George Wilkes y el abogado Enoch Camp, su fin inicial era describir con todo lujo de detalles los crímenes para, de este modo, ayudar a la policía a resolverlos. En I877, Richard Kyle Fox se hacía con la pro-

42 La Ilustración Artística, 17 de abril de 1899.

Cercles. Revista d'Història Cultural, 24 (2021), 47-78.

ISSN: 1139-0158. e-ISSN: 1699-7468. DOI: 10.1344/cercles2021.24.1002. 
piedad de la revista y, con una estrategia comercial y editorial atrevida, lo iba a convertir en el más leído por los norteamericanos.

Dos décadas antes de que Joseph Pulitzer o William R. Hearst protagonizaran la carrera por vender el millón de ejemplares, Fox había convertido su revista en ejemplo de publicación sensacionalista. Fue, también, modelo y fuente de inspiración de otra de las grandes publicaciones pioneras en el periodismo de sucesos. Se trata del semanario inglés The Illustrated Police News, cuya duración (I8641932) indica el éxito de la fórmula.

Tanto el Police National norteamericano como el Police News inglés aparecen como los modelos de referencia de lo que, en primera instancia, se llamó prensa de sucesos y, posteriormente, prensa amarilla de masas. En el caso de España, la palabra que identificará al nuevo género será la de «suceso» y la etapa de su irrupción la década de los ochenta. La serie de cabeceras con este nombre la inaugura, en I882, Los Sucesos. Revista ilustrada de actualidades, siniestros, crimenes y causas célebres, que en su número de presentación declara que aspira a ser «El Police Gazette» español. ${ }^{43}$ El semanario, con un formato tabloide, distribuía sus contenidos en tres páginas de texto y una de imágenes.

Sin embargo, la gran novedad en el género será Las Noticias Ilustradas, semanario creado por el dibujante Eduardo Sojo el 4 de febrero de 1883 , que marca un hito en el anquilosado periodismo español, pues, como lo calificaba El Liberal, "era algo menos que un periódico, pero algo más que un aleluya». ${ }^{44}$

En Las Noticias Ilustradas, Sojo escribía: «Triste es nuestra misión en la prensa, teniendo que impresionar a nuestros lectores con relatos siempre fatídicos de los innumerables crímenes que diariamente se comenten». Y, a continuación, se excusaba por hacerlo diciendo

43 Rosa María Rodríguez, "La prensa de sucesos en el periodismo español», Revista Internacional de Historia de la Comunicación, núm. 6, p. 26.

44 El Liberal, 5 de febrero de i883. 
que su tarea era ayudar a la justicia y provocar el horror al crimen en el lector. Casi compungido, advertía que iba a ofrecer una sección bibliográfica donde se anunciarían libros instructivos y con buenos propósitos, para compensar tanta sangre. ${ }^{45}$

Por mucho que Los Sucesos y Las Noticias Ilustradas abundasen en el crimen, lo alabasen como su sustento y lo vituperasen como horrendo, todavía no añaden el adjetivo pasional a ninguno de ellos. Las publicaciones periódicas especializadas en el nuevo género se suceden a un ritmo nunca antes visto: entre 1889 y I9I3, doce solo en Madrid. De ellas, la más destacada por tirada (más de Ioo.ooo ejemplares), duración y novedades en la oferta será, sin duda, el semanario Los Sucesos, de Domingo Blanco Misamigo. ${ }^{46}$ A partir de la segunda década del siglo xx, la línea que había separado el periodismo de sucesos del practicado por la prensa diaria o por las revistas de actualidad para las clases medias y altas desapareció. El mundo del crimen y de la tragedia lo impregnó todo, esto es, la obligación de competir y no quedarse atrás en las propuestas llamativas y sensacionalistas de cualquier medio provocó la transformación. Con todo, la fórmula de portadas llamativas, concursos ingeniosos, titulares exagerados, tiras cómicas e imágenes impactantes tuvo una clara continuidad en los años siguientes. El ejemplo más notorio será Las Ocurrencias, semanario creado el I2 de mayo de I9I2 por José Esaín Raymat, antiguo redactor de El Imparcial, que estaría en la calle hasta el 26 de diciembre de I9I3 tras haber publicado un total de I38 números. El periodismo de sucesos, tan denostado por algunos, había pasado a ser la locomotora del periodismo español. Y ahí sí, el cri-

45 Las Noticias Ilustradas, I8 de febrero de 1883, p. 2.

46 Uno de los periodistas más destacados del periodismo español cuya biografía es preciso recuperar, más allá del breve bosquejo ofrecido por Carmen MenÉndez, «Semblanza de Domingo Blanco Misamigo (e?-I943)", en Biblioteca Virtual Miguel de Cervantes - Portal Editores y Editoriales Iberoamericanos (siglos XIX-XXI), 20I7, http://www.cervantes virtual.com/obra/domingo-blanco-misamigo-salamanca--madridı43-semblanza-78846o/.

Cercles. Revista d'Història Cultural, 24 (2021), 47-78.

ISSN: 1139-0158. e-ISSN: 1699-7468. DOI: 10.1344/cercles2021.24.1002. 
men pasional descolló. Fijémonos en Museo Criminal, una revista quincenal aparecida en 1904 y que estuvo en los quioscos hasta 1909, año en el que cambió la cabecera por la de El Mundo Militar, para dar cuenta, con profusión fotográfica, de la guerra que España libraba en Marruecos; lo hizo hasta 1919. La intención de Museo Criminal era la de convertirse en los anales del crimen diario y proporcionar sensacionales novelas ilustradas, de asunto dramático, encuadernables y agradables al lector. En esta publicación, de forma evidente, los crímenes pasionales son menos crímenes:

$\mathrm{Al}$ parecer los crímenes pasionales no han disminuido desde el resonante proceso de 1898 , en el que fue condenada una mala pécora que había dado el pasaporte a tres maridos sucesivos. Esto ya es un colmo de actividad conyugal. ${ }^{47}$

El acto de un amante que mata a su querida es un accidente de la vida de aquel; pero el ladrón que mata, el exaltado que sueña con reivindicaciones imposibles, se hacen, a pesar suyo, profesionales de la criminalidad. $4^{8}$

Al lado del criminal de ocasión —citando a Lombroso-, del crimen pasional a que un exceso de fiebre ha conducido por azar, al lado del criminal habitual, hay el criminal instintivo, dado al mal por su organización íntima, por herencia tal vez. ${ }^{49}$

[...] las estadísticas unánimemente declaran que los crímenes pasionales aumentan en primavera y al principio del estío, esto es, en la época del hermoso y espléndido despertar de la naturaleza. ${ }^{50}$

Museo Criminal era una publicación próxima a la Guardia Civil. Uno de sus colaboradores era el capitán Ricardo García de Vinuesa

47 Museo Criminal, i de enero de I904, p. II.

48 Museo Criminal, Is de mayo de I907, 5.

49 Museo Criminal, I de julio de 1907, 4.

so Museo Criminal, is de mayo de i909, p. 6. 
y Arguedas, que había ingresado en la Benemérita en 1886 y que en 1902 prologaba El amor criminal, libro de un célebre policía parisino, Goron, cuyo objeto era, evidentemente, el amor pasional. ${ }^{\text {sI }} \mathrm{La}$ cuestión es que, inventando estadísticas o citando a Lombroso, la publicación remitía los crímenes pasionales a estados de enajenación pasajera y, lo que es peor, comprensible. Pero siempre y cuando el asesino fuese un varón, porque si se trataba de una mujer, entonces era «una mala pécora». Como en Museo Criminal, las citas a Cesare Lombroso abundan en la prensa de sucesos. En el semanario Los Sucesos, de Domingo Blanco, en un artículo que se intitula «La inferioridad de la mujer», se dice:

El profesor César Lombroso, resumiendo y comentando los trabajos del gran neuropatologista alemán Moebius, enumera los argumentos de este sabio para demostrar la inferioridad mental de la mujer. Ésta tiene el cráneo más pequeño que el hombre, no solamente como medida absoluta, sino también como medida relativa, según se observa en el niño. Es menos hábil en los trabajos manuales, puesto que en la costura y en la cocina, por ejemplo, el hombre ejercitado lo hace mucho mejor. La moral en ella no se deriva del razonamiento, sino del sentimiento; el amor y la devoción la hacen practicar milagros, pero solo en ciertos casos posee el sentimiento de lo justo. La mujer, dice Lombroso, no tiene más que 30 años de vida completa, y el célebre criminalista añade: «la mujer, siendo normalmente instintiva, debe incurrir en penalidades menores que el hombre; sucede con ella como con el niño, y cuando comete un delito es preciso tratarla como un enfermo mental», sobre todo cuando se trata de latrocinios, atribuibles a la cleptomanía. ${ }^{52}$

Aquí reside una de las claves para comprender la relevancia del crimen pasional en la prensa. En tanto en cuanto gira en torno a una

5I Alrededor del mundo, 24 de octubre de 1902, p. I7.

52 Los Sucesos, 20 de agosto de 1904, p. 3.

Cercles. Revista d'Història Cultural, 24 (2021), 47-78.

ISSN: 1139-0158. e-ISSN: 1699-7468. DOI: 10.1344/cercles2021.24.1002. 
mujer y en la época se tiende a pensar — con el influyente Lombroso y la criminalística balbuceante- que la mujer tiene una edad mental muy inferior a la del varón, los crímenes en cuestión se atribuyen a una degeneración de la naturaleza cuando los comete la mujer: no tiene características degenerativas y fisiognómicas especiales, aunque posee mayor virilidad de lo habitual, tiene la mandíbula más grande y sentimientos vehementes relacionados con los celos, así como un gran egoísmo, dice Lombroso..$^{53}$ Por contraste, si el crimen en cuestión lo perpetra un hombre de bien, entonces está movido por pasiones nobles; las bajas pasiones quedan reservadas para los delincuentes comunes. ${ }^{54}$ Así pues, en el crimen pasional todo es excepcionalidad: si lo comete la mujer, es una equivocación de la naturaleza; si lo perpetra un hombre, se trata de un crimen inspirado por la nobleza de sus sentimientos.

\section{Una feminidad y no otra}

$\mathrm{Al}$ articular nuestra hipótesis, llamamos la atención sobre la coincidencia en el tiempo del surgimiento de la expresión «crimen pasional» en la prensa - y, rápidamente, en la sociedad-y la emergencia de los primeros movimientos por la emancipación de la mujer. No lo hemos probado, pero podemos aportar indicios de interés. El semanario La Linterna, con el título "La tragedia de Valencia», publicaba en 1917 el siguiente asunto:

La coquetería es criminal siempre. La mujer coqueta es repugnante, despreciable, odiosa. Doña Concepción Arenal, en sus Cartas a un senor, anatemiza duramente a las coquetas.

53 César Lombroso y Guglielmo Ferrero, The Female Offender, Londres, Fisher Unwin, I895.

54 César Lombroso, Los criminales, Barcelona, Centro Editorial de Prensa, I9ı6. 
Doña Rosa Rodrigo es una artista que ha motivado en Valencia una tragedia. ¿Por su hermosura? No, no y no. ¿Por su arte? Tampoco. ¿Por qué? Por su execrable coquetería.

Un joven muerto y otro joven en la cárcel. Dos familias que lloran [...]. Ahora los empresarios de «variedades» correrán en busca de esta desgraciada, para contratarla; el público irá a verla, y será hasta capaz de aplaudirla; y algún torpe reporter, indigno de llamarse periodista, le proporcionará motivos de vanagloria macabra, homenajeándola rendidamente.

Todo esto es intolerable [...].55

Rosa Rodrigo era "una belleza griega", natural de la localidad valenciana de Almussafes, hija del secretario municipal, que aprovechó la Exposición Regional de Valencia de 1909 para presentarse a un concurso de belleza con la esperanza de lanzar así una carrera de artista, de canzonetista. No ganó el premio, pero fue finalista y cumplió su sueño. Primero, continuó formándose como cantante y pianista en el conservatorio y llegó a obtener la plaza de maestra de canto de las escuelas graduadas Cervantes de la ciudad de Valencia; luego debutó en el teatro, en I9II, con la zarzuela Les Barraques, de Eduardo Escalante. Cantaba en castellano y en la lengua local, el valenciano, y esto último la hacía especialmente simpática al público popular. Cosechó un enorme éxito. En I9I3 contrajo matrimonio con un acaudalado terrateniente local, Ángel Romero; dejó la escuela, pero poco tiempo después quiso continuar desarrollando sus cualidades como tiple. En I9ı6 debutaba en el teatro Romea de Madrid, en un espectáculo de variedades. Lo hizo con éxito y comenzó una gira que la llevó por diversos escenarios de media España, hasta recalar, en febrero de 1917, en los teatros valencianos. Y aquí se produjo el drama: el 25 de diciembre era asesinado Fernando de la Figuera, de veinte años, hijo del conde de Villamar. Su asesino, el pintor Tadeo

55 La Linterna, 4 de marzo de I9I7, p. 2.

Cercles. Revista d'Història Cultural, 24 (2021), 47-78.

ISSN: 1139-0158. e-ISSN: 1699-7468. DOI: 10.1344/cercles2021.24.1002. 
Villalba Monasterio, de 3I años, había acompañado a Rosa Rodrigo en alguna ocasión, pero esa tarde, tarde de toros, ella estaba con el hijo del conde en los tendidos del coso valenciano o así lo creyó el asesino, que entró poseído por los celos. Hubo palabras entre ambos; De la Figuera abofeteó a Villalba y unos minutos después este le descerrajaba varios tiros. Rosa Rodrigo declaró al juez que no tenía «intimidad alguna» con ninguno de los dos y que había ido a los toros, aunque allí los saludó a ambos. ${ }^{56}$ De inmediato la prensa se puso a buscar posibles culpabilidades de Rosa, que puso tierra de por medio marchándose a Lisboa. Con todo, Tadeo Villalba fue absuelto en el juicio... y Rosa Rodríguez fue hallada culpable de coquetería por $L a$ Linterna.

En el crimen pasional es fundamental quién desencadena la pasión. Es siempre sospechosa/o. La prensa siguió con atención el juicio, con lo que el caso estuvo en los periódicos durante dos años. El comentario de La Linterna hace algo más que culpabilizar a Rodríguez: coteja su nombre con el de Concepción Arenal, la famosa abogada y escritora, quien por lo visto condenaba la coquetería. La Linterna jugaba con las cartas marcadas. La coquetería se la imputaba a Rosa Rodríguez el periódico por voluntad propia, sin base en la instrucción del caso ni en el juicio del mismo. Arenal, por su parte, había escrito La mujer del porvenir (I869), defendiendo el acceso de la mujer a todos los niveles educativos y su autorrealización, así como denunciando la estrecha visión de verla solamente como esposa y madre: un buen ejemplo de todo lo cual pudiera haber sido Rosa Rodríguez.

56 El Diario Palentino, I de junio de I902, p. 2; La Correspondencia de Valencia, 7 de julio de I909, p. 2.; El Pueblo, I7 de enero de I9II, p. I; Las Provincias, 23 de diciembre de I9II, p. 2; Diario de Valencia, I7 de enero de I9I3, p. 3; La Correspondencia de España, I9 de abril de I916, p. 6; El Telegrama del Rif, io de septiembre de i916, p. 3.; Flores y Abejas, I9 de diciembre de I916, p. 5; El Adelanto, 26 de febrero de 1917, p. 4; La Correspondencia de Valencia, 26 de febrero de I9I7, p. 3; Las Provincias, 2 de febrero de I918, p. 2. 
La tiple prosiguió su carrera, pero de forma sincopada y sin el éxito del que gozaba antes de los hechos narrados. ${ }^{57}$ En 1928, tras una nueva gira exitosa —once años después de los hechos de Valenciadeclaró «mi vida ha sido una película». ${ }^{58}$ Cumplió, vale decir, "pena de periódico» en el marco mental del crimen pasional. El primer premio del concurso de belleza al que se presentó en igo9 lo había ganado Rosa de la Figuera, hermana del asesinado hijo del conde. Desde luego, de película, de esas en las que un encuentro casual en la juventud resulta sumamente premonitorio.

Es evidente que, a través del crimen pasional, La Linterna se decantaba por una feminidad vinculada a los estereotipos dominantes. En el fondo, su denuncia de la coquetería femenina es la condición para apreciarla como un arte de mujer, capaz de desencadenar la pasión.

Unos años después, Gran Proyector daba una noticia neoyorquina con el propósito de comentarla:

Nueva York. Se ha descubierto el motivo de que George Riley, de treinta y dos años, diera muerte ayer a su esposa, Daisy, de veintitrés, con la que solo hacía quince días se había casado. Una carta que el homicida había enviado a sus hermanas antes del crimen decía: «Dios me dice que mate a Daisy porque hay demasiadas mujeres en el mundo». La policía ha comprobado que el marido padecía de un sentimiento de inferioridad porque su mujer había conseguido un empleo en una fábrica de camisas, mientras que a él le era imposible encontrar trabajo. Siempre ha sido un problema que hubiera en el mundo más mujeres que hombres. Ahora, el feminismo ha venido a agravar considerablemente este problema. Pues no se trata ya de que siete mujeres hayan de entablar una lucha épica para disputarse al hombre que les corresponde en el reparto, sino que las siete mujeres se han puesto de acuer-

57 La Libertad, II de enero de I924, p. 4, y 7 de febrero de I925, p. 7.

58 La Correspondencia de Valencia, I4 de agosto de I928, p. 2.

Cercles. Revista d'Història Cultural, 24 (2021), 47-78.

ISSN: 1139-0158. e-ISSN: 1699-7468. DOI: 10.1344/cercles2021.24.1002. 
do para jeringar al hombre, quitándole los campeonatos de natación, las actas de diputado y los empleos [...]..$^{59}$

Así pues, la revista editada por Tomás Gutiérrez Larraya, sin tapujos, establecía el binomio: el feminismo agrava las nobles pasiones de los hombres... asesinos. El mismo imaginario social que La Linterna, convenientemente desarrollado.

\section{A modo de conclusión}

La noción de crimen pasional, de procedencia francesa, surge en España en I892: es la prensa generalista diaria la que comienza a difundirlo. Se aclimata con suma rapidez y se convierte en un tropo manido al poco tiempo. Su uso no decaerá.

El crimen pasional posee, en términos lingüístico-culturales, dos elementos que venían contribuyendo a la cultura popular en el arranque de su masificación. Por un lado, el crimen. Una larga lista de relaciones y pliegos de cordel había generado una representación de la criminalidad con hondo arraigo en todas las clases sociales, incluidas las clases populares. El folletín y la novela por entregas siguieron esa estela. Y a finales de siglo XIX, cuando Sherlock Holmes se hacía popular y el crimen de la calle de Fuencarral estaba en boca de todos, el crimen narrado sirvió para dar aliento a una prensa periódica que abandonaba sus viejos usos políticos y se planteaba como una aventura comercial en la que la obtención de dividendos era homologable a la de lectores.

Por otro lado, la pasión. El romanticismo, con su énfasis en el individuo y sus potencialidades, se había adueñado de ella, la había universalizado. Según Reyero, el amor romántico, expresión cimera

59 Gran Proyector, agosto de I930, núm. 3, p. 24. 
de la pasión, se vinculó a tres situaciones: «el amor conyugal y galante, que formaba parte de un comportamiento natural, la pasión irrenunciable, para la que no existían trabas morales, y la atracción física, desprovista de complejidad sentimental. Las tres situaciones tienen en común la existencia de deseo — un estremecimiento, una obsesión, la promesa de un placer- que envuelve a los amantes (o, al menos, a uno de ellos). ${ }^{60}$ Si la pasión ilustrada es controlada, la romántica es «vehemente y arrolladora». ${ }^{61}$

La pasión romántica —el amor romántico—y la prensa que se construía masiva se dieron la mano a finales del siglo XIX para crear el amor pasional y, con él, una representación social, en el sentido performativo que le confiere Chartier. ${ }^{62}$ Tanto es así que moldeó la práctica jurídica y, más todavía, el imaginario social. Téngase en cuenta, además, que, aunque en los códigos penales españoles —I822, I848 - no existió en concreto la figura del crimen pasional, sí existieron eximentes relacionados con el arrebato o los estados pasionales.

De su difusión se encargó la prensa generalista diaria, pero muy especialmente las revistas de sucesos. Aunque existen antecedentes -Los Sucesos de 1867, Las Noticias Ilustradas de I883 o La Gaceta del Crimen de I889-, se trata de un fenómeno periodístico del primer tercio del siglo xx español. Con la prensa satírica y sicalíptica, la de sucesos liderará las tiradas. Revistas como Los Sucesos y Museo Criminalde 1904, La Semana Ilustrada de 1906, Las Ocurrencias de I911, La Linterna de 1917, Los Sucesos Semanales de 1923 o Gran Proyector de I930, fueron proyectos que llegaron a enriquecer a sus editores y que

6o Carlos Reyero, «Amor, sexo y lujuria. Imágenes del deseo en el romanticismo español», Cuadernos de Ilustración y Romanticismo, núm. I5, 2007, pp. I45-I88.

6I Jean-René Aymes, «Romanticismo español y espiritualismo: afinidades y antinomias», en Y. Lissorgues y G. Sobejano, Pensamiento y literatura en España en el siglo XIX, Toulouse: Presses Universitaires du Mirail, I998, pp. 2I-36.

62 Roger Chartier, "Le sens de la représentation», La Vie des Idées, 22 de marzo de 20I3, http://www.laviedesidees.fr/Le-sens-de-la-representation.html.

Cercles. Revista d'Història Cultural, 24 (2021), 47-78.

ISSN: 1139-0158. e-ISSN: 1699-7468. DOI: 10.1344/cercles2021.24.1002. 
crearon un hábito en los lectores y el público en general, en un país que, con altas tasas de analfabetismo, seguía afecto a la lectura en voz alta en no pocas reuniones sociales. ${ }^{63}$

Los sucesos cubrían un abanico amplio de cuestiones, pero el crimen era la más relevante y, dentro de esta categoría, el crimen pasional se llevó la palma. ¿Con qué consecuencias?

El crimen vinculado al amor romántico no se narra, con lujo de adjetivación y detalle, en el hecho delictivo, sino en su transcurso, con el juicio y la sentencia, normalmente como último capítulo. Hemos comprobado que un caso podía rondar las páginas de una publicación durante dos años, lo que lo hacía familiar al lector. Lo que observaba el destinatario de la publicación era que el sexo de los involucrados construía el discurso periodístico. La mujer, víctima la mayor parte de las ocasiones, es culpabilizada por suscitar la pasión ajena, la del hombre o los hombres con nobles o lujuriosos sentimientos amorosos. El hombre, por el contrario, si ha cometido un crimen pasional, se aleja del asesinato y se acerca al homicidio: encuentra un atenuante que el periodista, las más de las veces, se encarga de adjetivar: es la ceguera que causa la pasión, la enajenación transitoria, el estar fuera de sí, el no ser dueño de su voluntad.

Hemos conferido importancia al hecho de que el crimen pasional surja justo en el momento en el que algunas mujeres de clase trabajadora y de clase media comienzan a involucrarse en movimientos de emancipación de la mujer; sin embargo, de momento solo es una coincidencia cronológica que habrá que investigar en términos de causa-efecto. En todo caso, nuestra hipótesis es que la prensa se sucesos, al apoyarse en el crimen pasional, fue un antídoto frente a tales movimientos de emancipación.

Convendrá seguir indagando en la textualidad performativa en el futuro, así como en las imágenes, de la prensa de sucesos. También

63 Rosa María Rodríguez, op. cit., pp. 22-44. 
será útil realizar comparaciones entre diferentes fórmulas de prensa sensacionalista y entre países distintos. Porque, de lo que no hay duda, es de que el crimen pasional moldeó la imagen social del amor romántico y de los hombres y mujeres concernidos por él durante el período estudiado en este trabajo y más allá.

Copyright (C) 202I. Aquesta obra està subjecta a una llicència de Creative Commons mitjançant la qual qualsevol explotació n'haurà de reconèixer els autors, citats a la referència que apareix a l'inici del document.

Cercles. Revista d'Història Cultural, 24 (2021), 47-78.

ISSN: 1139-0158. e-ISSN: 1699-7468. DOI: 10.1344/cercles2021.24.1002. 